\title{
12 Turkey
}

\section{Towards homegrown theorizing and building a disciplinary community ${ }^{1}$}

\author{
Ersel Aydinli and Julie Mathews
}

The International Relations (IR) discipline has existed in Turkey for well over half a century, yet in many ways it is still struggling to come together as a coordinated disciplinary community. Perhaps the most distinctive characteristic that emerges when trying to understand the discipline's development and current state is the complex and uncomfortable relationship it holds with the world of IR theory and theorizing. Over the past 15 to 20 years in particular, "theorizing" and the professional identities associated with how - and whether - one does it have resulted in a divide in the local disciplinary community between "theorists" (a title claimed by most) and "others" (a title generally bestowed by "theorists" on the rest). This divide splits along academic generations, educational backgrounds, professional interests, and socio-economic classes, and is inextricably intertwined with a desperate competition for disciplinary power. Ironically, given the pivotal role that theory has come to play within the local discipline, it is in the realm of theory in particular that Turkish IR has achieved the least. In this chapter we look at this inconsistency in Turkish IR by focusing on the issue of IR theory - when and how it was introduced to the local disciplinary community, the factors surrounding its emergence as a privileged and therefore often claimed disciplinary activity, and the forms of scholarly activity that fall under the title of "theorizing." We end by considering the prospects for change in these established patterns and the implications these might have on broader core-periphery relations within the discipline.

\section{Mapping the state of IR in Turkey}

\section{Monopoly of the Mulkiye}

The foundations for Turkish IR came out of the Mulkiye Mektebi, a carry-over from higher education during the Ottoman times, that has been described less as a school of international relations and more as a "vocational school" (Karaosmanoglu 2005: 137) for those preparing to enter state agencies, including a distinct track for those joining the diplomatic service. Instruction in the Mulkiye Mektebi focused on topics such as the teaching of diplomacy, diplomatic techniques, and protocol, with an added element of political indoctrination for those who would be representatives of the state abroad. This general approach and content continued - at least up until the late 1970s - even as the Mulkiye Mektebi was moved in the Republican era from Istanbul to the new capital of Ankara, and as it later came to be known as Siyasal Bilgiler Fakultesi (SBF, or Political Science Faculty). The curriculum became formally divided into administrative, financial, and political studies sections. A distinct IR track within the school was established by the 1950s, and produced its first Ph.D. student in 1956 . 
In those early years of the 1960s and 1970s, the Mulkiye held an incontrovertible monopoly over training and scholarship in the field of IR. Although a few other faculties offered somewhat related programs, such as economics and trade or administrative sciences, the prestigious Mulkiye was the only one that truly mattered, as its graduates alone were eligible for service in the Foreign Ministry. Small and exclusive, the Mulkiye became the world of the elite. A grooming ground for future diplomats, policy-makers, or policy advisors, the curriculum focused on diplomatic history and international law, and served a student body which, more often than not, was made up of the children of the country's wealthier families, often past diplomats and policy-makers. These students were not only familiar with the world they were training to enter, but had the foreign living experience and often the language skills to ease their transition into the field. Professors in the field were often diplomatic historians or retired diplomats. In fact, this description of the Mulkiye is not unlike those of early IR in the U.S. in the first half of the twentieth century, which has been described as a discipline dominated by "enlightened men of learning and leisure," and noted for the unclear boundaries between academia and politics (Wallace 1994: 140).

With the entire local IR disciplinary community essentially reduced to one department, whatever happened in that department had a huge impact on the local discipline. The retirement of certain faculty members, the firing of others, or the particular politicization of the Mulkiye students and faculty, had the potential to disrupt the overall progress of the local discipline. Major national events, such as political disruption within the country in the 1970s, or the coup of 1980 were all reflected in the department. When a significant percentage of the Mulkiye faculty were fired or sent to jail after the 1980 coup, it took nearly a decade for the department - and thus the discipline - to recuperate and regroup. (Though, of course, one could equally argue that this huge upheaval actually helped the local IR community in that it finally allowed other departments to emerge from under the Mulkiye's shadow, as will be seen below.)

The Mulkiye excelled at producing well-informed policy-makers and diplomats, but neither the school's Ottoman-age style of teaching and learning nor its primary curricular focus on policy was conducive to the development of theory and theorizing, a criticism raised early on by a leading faculty member (Bilge 1962). Teaching and learning was based on discipline and memorization, with minimal requirements for reading but rather a focus on taking vigilant notes from the professors' lectures and writing exams based on those lectures. This style did not accommodate critical engagement with the ideas being presented, nor did it promote reading diverse material and comparing and evaluating arguments, all of which are essential aspects to conceptual development. Rather than being questioned, the style remained largely unchanged over the years as those students who performed best in this system were taken on as graduate students and eventually faculty members. One could hardly expect theoretical breakthroughs to come out of such a context.

Moreover, the fact that the graduates of this leading department for IR in Turkey almost all went on to serve in the Foreign Ministry meant that policy-relevant research was dominant in the Mulkiye, and thus in Turkish IR - at the expense of theory. As is the case in most of the world, the policy community was not then, nor is it now, necessarily sympathetic to theoretical works. A retired Turkish diplomat recently expressed his belief that "theory and practice do not fit," and that theory does not "provide solutions" to urgent problems (personal communication 2007). Unsurprisingly, when the Turkish Foreign Ministry sponsored Mulkiye faculty members to produce the first volume on Turkish foreign policy, a book that would constitute the primary textbook for generations of future IR students, they particularly demanded a descriptive, policy-relevant work, not theoretical abstractions. In its training and 
scholarship, therefore, the Turkish IR community was in its first decades entirely focused on Turkey and on meeting the demands of daily foreign policy issues and foreign policy-makers.

\section{An expanding discipline}

In the 1980s, the growth worldwide in the number of IR departments and students began to strike Turkey as well. Following the 1980 coup, the newly formed Higher Education Council, designed to bring under governmental control the universities that had served as the front lines for much of the political turmoil of the 1970s, also sought to streamline various university programs. Departments of Economics and Trade or Administrative Sciences that existed at a handful of universities in the 1970s were renamed in 1982 as Departments of Political Science and Public Administration. Either as part of these or as newly developed separate departments, instruction in International Relations was included. While numerically the 1980s witnessed this increase in IR departments, the instruction in these departments for the most part followed the Mulkiye tradition of treating IR as a combination of international politics, international law, and diplomatic history. The one possible exception to this rule was the Department of IR at Middle East Technical University, where an effort was made to instead introduce two main tracks of theoretical studies and area studies (Middle East and Europe).

Along with an overall opening up and political liberalization of the country in the 1980s and the 1990s, the discipline saw not only a numerical growth but an increasing number of students from non-elite socio-economic backgrounds joining International Relations programs. This was not due to a particular effort to include a broader demographic base of students, but can probably be simply linked to the growing numbers of students being admitted into newly created IR departments. With the influx of students there was a dividing of the student body between the small numbers of elite who had traditionally made up the full population and a still small but growing minority of non-elite students - as noted in the words of some self-described "non-elite" students of the era:

In the classroom you could always tell who was who because the aristocrat kids all sat together. There were only a few of us kids from poor backgrounds and we always sat together too....

I came from a family that was not rich . . . I started out in IR to be a diplomat. To be a diplomat, a Turkish representative abroad, it is a very interesting and challenging task. But in the later stages, say, in the middle of my undergraduate education, I understood it was very difficult for us to enter the foreign ministry because of some, well, obstacles.

I soon realized it was practically impossible to become a diplomat because I only had weak German skills, and I didn't know French or English.

The divide between the elite and non-elite operated like a domestic core and periphery - with all of its accompanying restrictions. With the domestic "core" dominating the discipline in foreign policy, the domestic "periphery" faced a struggle, complicated by their lack of family connections and foreign language skills. As a weak but growing minority group that was gradually advancing up the ladder of the local disciplinary community, it is unsurprising that the domestic periphery students would seek new ways of proving themselves, new ways to compete, and new means to compete with - ways and means that were not within the exclusive control of the domestic core. 
At about the same time - the mid-1980s and the early 1990s - there was a push by the Turkish Ministry of Education and later by the Higher Education Council to send large numbers of students abroad for graduate studies. This coincided with the opening of several new universities across Turkey and, among them specifically, the launching of 13 new departments of IR. The peak of the foreign studies effort was the 1993 to 1995 dispatching of more than 4,000 students, who were intended to return and make up the faculty for these newly opening universities. To give a sense of the concurrent scope of growth of the IR discipline from those years up until the present, in recent years the number of undergraduate students enrolled in IR departments has reached nearly 13,000, up from 1,800 in 1986 and from only a couple of hundred at any one time in the 1970s. By 2005 there were over 200 Ph.D. students alone registered in IR departments across Turkey. Turning to faculty members, from only a handful throughout much of the early decades of the discipline (even by 1986 there were only 13 actual professors - assistant, associate or full - of IR), in recent years the number has topped 400 and is growing.

Turning back to the early 1990s, for the discipline of IR in Turkey, graduate study abroad for more than just the occasional individual student was a dramatic - one might even say revolutionary - turning point. For these scores of students of international relations, studying in North America or Europe meant being exposed for the first time to the world of IR theory, and in many cases to the understanding that producing theory was the highest role to achieve in the discipline. Significantly, many of those studying abroad were not from the traditional elite. The nature of the 1993 to 1995 scholarship program was such that for the first time, masses of students from all geographical and socio-economic backgrounds were able to go abroad for graduate studies - including in the field of IR. In this case, the "de-eliticization" of the student body, and ultimately, faculty of IR was a more deliberate one, brought on by a Higher Education Council president who pointedly strove to make the scholarships accessible to students outside of the main cities and without the advanced foreign language skills that mark a private school education in Turkey (Mathews 2007). For these non-elite IR students/junior faculty returning to Turkey, "theory" meant a new area in which they could compete and excel without family connections. Armed with Western knowledge, the domestic "periphery" began using theory as a shield to balance against the domestic core and even to penetrate the core itself.

Throughout the 1990s, we can see a growth in works of a generally theoretical nature being produced by Turkish IR scholars, as one scholar after another tried to show himself (or frequently, herself, as the numbers of females in the field were also on the rise) as more "theory-driven" than the rest, or simply, as one IR scholar who was an assistant professor at the time, says, "to try and prove to people that they knew theory." To draw an analogy with IR terminology, what we see in the 1990s is a grand-scale literary attempt at balance of power. To balance against the older elite generation of IR scholars (and their traditional discourse of diplomacy, history, and international law), the younger, often non-elite products of the foreign study-abroad programs began making use of the means of the Western IR community - the discourse, genres, and topics of IR theory.

There is no doubt whatsoever that they were successful in their goal of balancing against the local IR elite by introducing a new and powerful discourse to the Turkish disciplinary community. It is difficult to find an IR scholar in Turkey today who will not in some way attempt to explain how his or her works incorporate a theoretical perspective into their analyses. The prioritizing of "theory" has become so widely accepted that scholars of all backgrounds try to claim their position as "theorists," but it is most noticeable among the generations of the late 1980 s and afterwards. The phenomenon manifests itself vividly when 


\section{Ersel Aydinli and Julie Mathews}

you hear Turkish IR scholars say something along the lines of, "Yes, I write primarily about Turkey ... but I do it in a theoretical way." The two following excerpts from interviews with scholars who completed their Ph.Ds in England and returned to Turkey in the early and the mid-1990s not only reveal the attempt to identify themselves as part of the new, "theoretical" community, but also to draw a generational line between themselves and the past:

The scholars in Turkey before the 1990s focused on Turkish foreign policy issues, or some other empirical, national issues . . . case studies. Nowadays in Turkey I see that, like me, some other scholars have started to teach theories of IR. This should be taken as a positive contribution made by the new generation of IR scholars. Of course, still the majority of IR scholars in Turkey focus on issues which are concerned with Turkey or Turkish foreign policy ... this is normal, most of the time we are occupied by national problems and issues. Because of this I am very sad to say that I am one of those whose writings are concentrated on issues of Turkish foreign policy. But, what I try to do even as I am studying and writing on these issues, I try to look at the problem in a theoretical perspective.

Or another scholar:

IR teaching began in the 1950s in Ankara University. The people who were teaching there were imported from diplomatic history or international law. Even in the 1990s when I came back from England I found the tradition was still the same. When you talk to people they wouldn't admit this, but you have to look at how they teach in their classes or how they write their books, and when you look at those, you'll see that most of the IR writing and teaching in Turkey in the early 1990s was still using the tools of diplomatic history, not social science research tools. And still this is very much a problem. Turkish IR is not grounded in theory, it's mostly about Turkish-Russian relations, or Turkish-Iraqi relations between certain years. My own writings tend to be about Turkish foreign policy too, but I try to distinguish myself. The difference between a couple of guys and myself and the rest is that since we have this IR theory understanding, I start by developing a big picture and drawing a framework, then start analyzing the issue.

When speaking to those older generation members who were themselves educated abroad, the divide becomes less clear, and the overall theory issue takes on greater complexity. While most senior scholars generally recognize the importance of theorizing both in the core and in the local IR community, they are sometimes more willing than the younger scholars to admit that they generally don't "do theory." One senior scholar dismisses one of her own works somewhat bitterly:

This is purely empirical and descriptive, a product of my own research. It has no link to a body of theoretical literature on the topic because I never had a chance to look at that literature. And I seriously doubt I will have a chance.

One of the very first Turkish scholars to go abroad and receive training in IR theory at a prestigious U.S. institution in the late 1970s blames his admitted lack of theoretical works on time constraints and easier alternatives, and draws attention to a dilemma of the older 
generation's finest academic potential being drawn prematurely into leadership roles that prevented them from doing challenging, theoretical research:

When I returned to Turkey the discipline was so small here that I immediately became promoted and took on important administrative duties. This kept me extremely busy. I had to build up our department. It still keeps me busy. So when people come to me and ask, I write chapters for their books, usually concrete things on Turkey's relations with Europe, European politics, and so on. Since I don't have much time to publish, I like the work because easily then I can publish. . . . If I were able to work in my own tempo, I could probably have formed my own agenda more, looked for different publishing spaces, journals . . . but I don't have the time and there is always the demand. I work according to that demand.

Still another senior scholar, one well respected and published internationally, carefully keeps the door open to the idea of his own works having at least a "theoretical perspective," but dismisses overall the assertion of any actual "theorizing" being done in Turkey at all:

As you know, I'm not doing theoretical work. Nobody's doing theoretical work in Turkey. I'm rather doing policy-oriented work, but I use IR theories.

His statement raises the obvious question of what we mean when we speak of "doing theory." Do we mean "using" IR theories? Do we mean - as implied in the previous quote - drawing a framework before analyzing? Or do we mean something else?

\section{Categories of theory}

Attempting to define the "types" of theory being somehow used or applied in the research and writing practices of scholars in the Turkish IR community is a complex task, and one which could undoubtedly result in very different answers. Our effort here draws on and compiles the ideas of various Turkish IR scholars on this issue, taking into consideration the purposes these various types of theorizing serve for these scholars in terms of their professional development and advancement in Turkey. Despite some slight overlap, it is possible to define four general categories of what has been considered and labeled by Turkish IR scholars as "theorizing": pure theorizing, homegrown theorizing, application, and translating.

\section{Pure theorizing}

The same professor who claimed that "nobody" is doing theoretical work in Turkey explained in this way what he meant by theoretical work:

Pure theoretical work, which is to be published in theory journals like International Organization, International Security, or International Studies Quarterly. Original theoretical work ... no work like that is being done here. Sure, there are some people doing some kind of theoretical work in Turkey, but they don't publish it in good journals. Most of it is published in Turkish and they are borrowed works. They repeat what the theory people are saying in the U.S. You see, they are translations.

His description of pure theorizing resembles others' efforts to distinguish types of theorizing, in particular Lepgold's "pure" theorizing category (Lepgold 1998), which specifies that the 


\section{Ersel Aydinli and Julie Mathews}

goal of such "pure" or "referent-free" theorizing is to find coherent explanations for broad phenomena while remaining unattached to specific areas. Such a definition would be questioned by some as unattainable. As one young Turkish IR scholar pointed out to us, "You won't see an Alexander Wendt in Turkey because Wendt was writing from Wisconsin!" In other words, even if actual theory construction does take place in Turkey, it will not likely be the same as that carried out by core IR scholars. His point recalls Cox's well-known position that so-called "pure" theorizing is in any case affected by the contexts in which the theorist operates. The questions theorists choose to speculate on, the ways they choose to do so, and the interpretations they give to the answers they find, are all affected in multiple ways by the theorists' own backgrounds and the social worlds they interact with. This debate temporarily aside, any existing theoretical literature that does not explicitly address a particular country may be considered for the moment as "pure" theorizing.

\section{Homegrown theorizing versus application and translation}

A second category of theorizing may be found in the words of a junior scholar who spoke of her aspirations to produce original theory based on local contexts and questions:

I would like to be someone who can combine theory and policy. I would like to first take the theories that the core produces and use them in my efforts to explain things in Turkey. But better yet, I would like to be someone who could not only explain things on a conceptual level, but also somehow build up some original perspective out of looking at Turkey's international relations or Turkey's experiences. That's my goal. I would call myself really successful if I could come up with a work identified as an original theoretical perspective originating out of these lands, out of Turkey or Turkey-like countries. That would certify that knowledge has accumulated in this country and finally produced something.

We can conceive from this statement of a second level of theorizing, a "homegrown" theorizing in which entirely new patterns, understandings, and frameworks of analysis are sought through the construction of theories stemming from "local" experiences. These "local" experiences do not mean simply the last century's history of the Turkish republic, nor does it mean that the resulting theoretical activity is relevant only to Turkey or her neighbors. Examples of "local" Turkish contexts out of which theorizing might come include the context of mid-size powers in global affairs, Islamic democracies, former Empires, democratizing countries located in anarchic regions, or multicultural nations. These and many other categories describing aspects of Turkey's past and present could provide valuable starting points for original, homegrown theorizing. Homegrown theorizing may also involve existing theoretical questions or debates, but using local experiences, history, and contexts to locate gaps within and build on to those existing theories.

Following this level is a third, the one that most Turkish IR scholars seem to mean when they say they "apply a theoretical framework." This "application-level theorizing" has various subcategories of its own, but at its most basic seems to refer to leading off a written work with some kind of literature review, rather than jumping straight into a description of the particular event or issue. At a slightly more sophisticated level, application may also refer however to those scholars who take an existing theoretical model, and draw on the Turkish or regional experience to provide evidence of the model's usefulness as a way of looking at things. Thus, for example, a study using a constructivist approach to explain Turkey's relations with the 
EU is a form of application theorizing. Application theorizing may also be nonconfirming if the local context is used as a ground for "testing" and finding fault with an existing theoretical approach or body of literature. A subtle distinction may be made between such nonconfirmative application theorizing and actual homegrown theorizing in that the latter should either introduce an entirely new approach or perspective (based on the local context but applicable beyond it) or should at a minimum draw on the local context to add original perspectives or concepts addressing shortcomings or gaps in an existing theoretical approach.

An interesting example (though a missed opportunity) of how homegrown theorizing might take place comes from balance of power theory. At a time when the prevailing Waltzian view was that countries balance against rising powers, Stephen Walt looked to the Middle East and alliance patterns there and wrote that in fact they balanced against the threat potential (Walt 1987). The work received great attention and admiration, and quickly became part of the core theoretical literature. While legitimate questions can be raised as to whether such a reformation of an existing theory, coming from a local Middle Eastern scholar, would have been received with equal praise by the core, it would (at least hypothetically) have been a powerful example of homegrown theorizing. The irony from this example is that at a time when most Middle Eastern "theoreticians" were teaching and translating Waltzian balance of power theory, Waltz's own student was busily using the local neighborhood to further the original theory.

Finally, there is a fourth level of theorizing, implied by the earlier cited senior professor's reference to "borrowed works." In this case, someone writes a piece in Turkish that basically translates ideas or concepts that have already been expressed abroad. This "translation-level" theorizing would include works that provide overviews of particular core theoretical paradigms or perspectives, translating them into Turkish to make them accessible to the average Turkish IR student. It also happens to include the major textbooks of IR (e.g., Gonlubol 1993; Sonmezoglu 2000; Ari 2002), which present in Turkish major ideas from the Western disciplinary community.

By numbering these levels of theorizing, the intention is not to prioritize them in terms of value, though there is a logical progression in a disciplinary community of one building on the other. Not only homegrown theorizing, but all levels should be seen as necessary and interdependent elements in the process of community-wide theory-building. Translations are necessary to expose the broader disciplinary community, beyond those few who have access through language and study abroad experiences, to existing theoretical ideas. For example, as-yet-undeveloped theoretical ideas and concepts may be hidden in areas of Turkey where the very idea of "IR theory" and its use is available only in translation. Such unexplored ideas and concepts could include ideas on multiculturalism (experienced in the southeast of Turkey), or conceptualizations of religious coexistence (as may be found in Central Anatolia in the writings on human-centric peace by Rumi). In order for such potential theoretical ideas or concepts to be explored, the scholars familiar with them must be aware of the purposes, goals, and value of theorizing - yet these scholars are very often unable to access these ideas and gain this familiarity due to limited foreign-language skills. A first step therefore is to ensure that widely known theoretical concepts in the international IR community are made available through translations to the full Turkish IR disciplinary community. Applications of existing theory are also necessary, both to add confirmations to those existing theories (of use to the larger disciplinary community) and to provide examples of and practice in the use of theory (of use to the local community).

Having said that all levels are important, the experience in Turkish IR over the past 15 to 20 years has shown instead that a hierarchical perspective is generally taken. There is the 


\section{Ersel Aydinli and Julie Mathews}

tendency for Turkish IR scholars to either deny the existence of or to put down others' theory efforts as less important than their own. Thus, scholars involved in the translation of theory criticize those who do "only" policy studies, scholars doing some form of application theorizing tend to criticize the translators, and scholars who participate in homegrown theorizing put down the application studies.

Confusing matters further, differing interpretations or misrepresentations of what may or may not constitute examples of certain levels become manipulated for purposes of building up professional identities or supporting professional rivalries. Scholars sometimes claim to conduct different levels of theorizing than they actually do. In most cases there is just a general claim to "theorizing," but in others there is the implication that scholars are conducting, for example, "pure" theorizing, when, according to our definition, their works would more likely fit under the heading of application studies. For example, a scholar claiming to be a "theoretician" because s/he works on questions of strong state traditions in anarchic environments, but who explores this issue by using existing neo-liberal concepts and frameworks to analyze the Turkish case, is doing application-level theorizing.

There may be a very few examples of Turkish scholars now who participate entirely in existing core theoretical discussions at an abstract level, without any reference to Turkey. If these scholars are truly doing this without any connection to Turkey or to regional experiences, if they are, in that sense, indistinguishable from their core colleagues in terms of the contribution they are making to that theoretical discussion, then in light of Cox's arguments that there can be no truly "context-free" theorizing, it would appear that such scholars were in fact fully assimilated into the core disciplinary community, and can no longer really be categorized as "periphery" scholars.

\section{Still underachieving}

With the monopoly of the Mulkiye broken, and with the numbers of IR departments, students, and foreign-trained scholars skyrocketing in the past 15 years, why is it that we see only a booming of application-level theorizing (and a domination in recent years of applications of critical theories and approaches)? Why is there still an underachievement of homegrown theorizing?

\section{Periphery-based causes}

Perhaps the first reason for this underachievement is the fact that although talk of theorizing has become commonplace, its use has not been for purely academic purposes. With theory being used as a "balance of power" tool, its practice often remains elusive, unsubstantiated, and shallow. IR departments have seen cases of professors who have never undergone graduate level exams in IR theory or perhaps have never even taken a comprehensive, graduate-level IR theory class, becoming known as "theorists" and being assigned the task of training future Turkish IR scholars in IR theory simply because they have come from abroad. In many cases this results in teaching a very limited picture of IR theory - focusing on whatever theory(ies) the professor is familiar with, from selected epistemological and methodological approaches to formal IR theories. Over the years this has led to the importation into Turkish IR of waves of theories and approaches - whatever represents the cutting edge at the time of the professor's own foreign study experience. Students become exposed to a particular wave and remain unaware of the fuller spectrum of theories, concepts, and approaches. Such a pattern prevents any accumulation of debate over IR theory in Turkey 
as each successive generation dismisses or fails to recognize any value in the previous generation's efforts.

Many other factors have contributed to the lack of homegrown theorizing. As scholars here point out, even without the Mulkiye monopoly, training in analytical thinking remains underemphasized throughout the entire Turkish educational system, and memorization-based learning still prevails. This style rewards replication and eliminates any real need for learning alternative ways of looking at subjects. There is little investment in methodology training in Turkey, and thus training in the art of scholarship remains extremely weak. Even the leading IR departments often fail to recognize the value of teaching methodology, with some having done away with or at least questioning the value of having separate methodology courses for their graduate students. A former chair of a leading IR department connects the lack of methodology with the underachievement in theorizing when he says that Turkish IR "never promoted the value of comparative studies, and therefore learning about other cases, comparing, producing generalizations, remained weak. We only studied our case. Without generalization, theorizing becomes impossible." The natural outcome of this single-minded emphasis on the Turkish case has been a limiting of chances for theorizing. Either the lack of or poor quality of methodology training results in students/scholars skipping the crucial stage of "pre-analysis" that must occur in theoretically based scholarship. Clearly defining the research question, locating a gap in the theoretical and empirical literature, discussing alternative methods for analyzing the question, identifying appropriate theoretical framework and methodological tools - all of these stages critical to both theorizing and well-argued research receive only passing attention.

Ironically, given the importance apparently given to theorizing on the level of selfidentification within the Turkish disciplinary community, many IR scholars nevertheless note that in Turkey theoretical work simply doesn't pay back - it doesn't get you media coverage or project funding and it doesn't even guarantee you a better job (a process still sometimes based on personal connections and a touch of luck). Theorizing is considered by many therefore as a luxury. Two professors from leading Turkish state universities both referred to the envy they felt for their European and North American colleagues, whom they believe are able to gain special professional recognition for theorizing and publishing theoretical works in particular venues, whereas in Turkey they are kept overly busy with teaching (often having to supplement low pay standards by teaching extra courses at private universities) and are not recognized for serious publishing efforts. In the words of one, "They don't slap your face if you publish, but they don't pat you on the back either.” Instead, recognition, status, and money for the Turkish IR scholar is still more likely to come from writing policy pieces - these get you television spots, invitations to write newspaper columns, and opportunities for government contracts.

A deeper structural problem that works against the possibility of conceptual works being produced here is the lack of established criteria for publication standards. In the West, the most prestigious journals often have a theoretical emphasis. Since publishing in them carries the promise of widespread recognition, promotion, and better employment, the effort seems worthwhile. In Turkey there remains little incentive to opt for the seemingly more difficult venue of theoretical research. True, for promotion in Turkish universities a greater number of points are now credited to articles published in Social Science Citation Index journals, but the overall total requirement of points remains very low, so points can easily be achieved through other routes. Among these other routes are Turkish-medium, non-theoretical journals, among which there is little in the way of agreed-upon standards. When an article quickly published in a newly launched "refereed" journal out of a newly established IR 
department in a new university in rural Turkey can be counted for academic promotions across the country, why struggle against huge odds to get published in International Security?

In order to set such standards, and therefore even more critical for the long-term development of theorizing from the local IR community, there is the need for a cohesive, conscious, organized, and institutionalized Turkish IR disciplinary community. This community should have a yearly convention, a flagship journal, and a national index of acceptance criteria to evaluate Turkish publications as well as standards for quality research and training. Unfortunately, even after 50 years, such a community does not yet seem to exist.

Evidence of the Turkish IR community's lack of such cohesiveness and organization may be seen in the fact that there have been only a handful of occasions in its history when scholars have come together to discuss the state of the discipline. Two early meetings, in 1959 and 1961, were followed 35 years later by a third, a fourth in 2001, and the most recent in $2005 .^{2}$ Except at the last of these meetings, the participants were exclusively from Ankara and Istanbul - reflecting the ongoing division of the domestic core and periphery. More disturbing from the view of disciplinary development is the observation made in 2005 by a senior scholar who was personally familiar with the earlier meetings, that in all of them the challenges and questions debated remained the same: what is IR, what should we teach, and how can we build an IR discipline (Onulduran 2005)? Clearly little or no progress has been made on these most basic of questions, a sobering note suggesting that Turkish IR remains at best a loosely knit, fragmented community, unable to build a coherent accumulation of research agendas and findings or offer suggestions for future research.

\section{Core-based causes}

Turkish scholars are of course not the only source of blame for the lack of Turkish theorizing. A large share must fall on the core, where training patterns, advisor-student relationships, core prejudices, and scholarly competition all tend to push the periphery student and scholar away from engaging fully in theoretical discussions. Examples from the experiences of two Turkish scholars may strike familiar bells with other periphery students who have studied in the core. In one case, a female IR scholar reported asking for advice on how to pursue IR-track studies in her political science department from a Turkish scholar who had lived and worked in the U.S. for many decades. His response was, "You might as well go right into comparative politics. We all start off in IR, and we all end up in comparative politics." Yet another scholar who studied in Europe in the early 1990s reported experiencing the same attitude:

Core scholars are looking for people to work on their theories and prove them in new lands so that they can tell their colleagues that their ideas are being read about and applied in China or the Middle East. They aren't looking for new theoreticians. They're looking for native colonials to sell core products in new lands, whether these are new epistemological fixations or hardline methodological preferences or concrete theories. The best they do for their developing world pupils is perhaps to force them into applying their own theories. Of course, when they tell them to do this, they don't expect them to question or revise those theories with some Oriental input. The problem with this though is once the pupil adapts the advisor's theoretical identity and assumes this confirming role, it's very hard to make the jump to a critical, revisionist mode for generating new theories. Once you become the agent and franchiser of someone, it's not easy to try and produce your own product. We see McDonald's pushing aside the old age kofte stands in Turkey in the same way. 


\section{Prospects}

On the Turkish front, there are several hopeful signs that we will see greater achievements in IR theorizing in the years to come. The fact that three of the handful of Turkish IR disciplinary gatherings have taken place within the past decade suggests that there are increasing efforts for community-building and for coming to terms with the challenges that face the local discipline. The 2005 gathering in particular was exceptional in the sense that it gathered together the domestic "core" and "periphery." Though the minutes of the meetings show that core voices still remain dominant, the effort gives hope that a relatively integrated Turkish IR community can grow before this distinctive domestic core-periphery structure becomes further consolidated. Useful ideas to this effect came during the meeting from a senior scholar and graduate of the Mulkiye, who proposed that scholars from rural Turkish universities be encouraged to teach as visiting scholars at the leading universities in the major cities, thereby allowing them to play more active roles in the community. She also suggested developing a program to support these scholars' attendance at international conferences (Sezer 2005: 113). The good news is that these ideas are already being partially supported by government policies. The Scientific and Technological Research Council of Turkey (TUBITAK) is organizing a program to promote scholarly exchanges within Turkey, and the Higher Education Council is working to place graduate students from rural areas for training in the domestic core universities, so that they will later go back to teach in periphery institutions.

In terms of Turkish publishing venues, the 1990s witnessed an explosion in the number of think-tanks in Turkey and consequently in journals reflecting the policy priorities of these think-tanks. At the same time, major universities shied away from publishing journals. There seems however to be some signs of a shift. Though not coming directly out of a university, the new journal Uluslararasi Iliskiler Dergisi (International Relations Journal) was launched by two SBF professors, and appears to be an exception, promoting the publication of theoretical research. Another hopeful sign of community-building and progress is the now annual international IR conference held at Middle East Technical University - a conference that tries each year to combine theory, policy, and area studies.

\section{Homegrown theorizing and becoming a community}

If these trends continue, and if able and interested scholars begin producing increasing examples of successful homegrown theorizing efforts, these activities may become the driving energy behind a new image and substance for the Turkish IR community. Turkish IR still seems mired in questions about what the discipline should be doing. IR communities in the West have not necessarily resolved their existential debates about "what is IR?," but have rather gone beyond these basic questions by building up long-term research agendas and research paradigms often based on "great debates" - e.g., realism vs. idealism. These Western communities have become communities through hands-on practice of IR, not through metacognitive debates of the question. The growth of homegrown theory in Turkish IR can play a similar leading role in defining such debates, from epistemological and methodological questions through the formation of formal IR theories. It is surprising, for example, that given Turkey's critical relations with the European Union, Turkish IR over the years has not taken a leading role in debating and contributing to integration theories.

Turkish theorists can also take a leading role in helping fight the IR community's fears of infiltration of poor-quality scholarship, of an epidemic of "conspiracy theorizing" (attractive 
to the masses in its simplicity and parsimony but empty of methodology), and an overlap between journalism and IR. It has been pointed out that these challenges to the discipline are best met by standing firmly behind vigorous theoretical and methodological work with global standards (Dedeoglu 2005: 49; Kut 2005: 51). Turkey's theoretically inclined IR scholars should draw on their own training, produce quality examples of scholarship, and make clear the differences between scholarly research and speculation.

Of course, such noble efforts cannot be achieved unless the quality of the research supports it. "Theorizing" will have to come to mean more than just a balancing tool, and simply claiming to do theory can no longer be enough to provide ammunition for self-identification and superiority. The burden of going beyond the current image, misrepresentations, and misuse of theory lies with those who claim to be theorists. Turkish scholars have to recognize that theory does not mean better, but in fact demands the close support and cooperation with case studies, area studies, and policy studies. This attitude must be transferred in the classroom. Teaching IR theory both in the U.S. and in Turkey has shown us that if you fail to communicate to students the use of theory for their needs and contexts, you immediately lose the goodwill of a large portion, and may even encounter resistance from those heading towards government work or area studies. The Turkish IR theory classroom must be the front line in calling a halt to the local disciplinary community's domestic core-periphery structure before it becomes consolidated under labels of "theorists" and "others."

\section{Homegrown theorizing and core-periphery IR disciplinary relations}

The question remains as to what such positive developments in local IR theorizing might mean for future relations between the Turkish and core IR communities. Turkish IR scholars currently complain that their attempts to have their voices heard in core IR theoretical discussions go unheard. Their scholarly efforts, when recognized by the core, seem to hold importance only as far as they represent a national view (e.g., a Turkish perspective on the Iraqi situation, or a Turkish perspective on energy politics in Eurasia). As one senior IR scholar noted several years ago:

What happens is that you become good for area studies. So I do get to teach at good universities in the U.S. and Europe, but it's all on Middle Eastern politics. And when you get invited to conferences, it's not for the contributions that you might make to theory or conceptual thinking, but more to sort of case studies, or area studies, or sort of empirical descriptive analyses, and that, to be honest, hurts. That hurts.

His dismay extended beyond the personal affront, however, to concern over the resulting construction of disciplinary knowledge in such a compartmentalized environment:

What I have noticed over the last few years is that I find colleagues in the West slipping into generalizations, and theorizing that is really remote from what one might consider as the reality out there. And that really is at times almost scary. What happens is that maybe the lack of very in-depth knowledge of cases or areas by and large leaves this group ignorant of all this, and then they get involved in an exercise that reinforces each other. And when, say, someone like me comes in and I throw a question at them, it really generates a moment of silence, and we can sense that the whole thing is thrown off balance. There is a moment of insecurity there, but it's only a moment and then they push on. 
In such an environment, what might an increase in homegrown Turkish theorizing mean for local-core disciplinary relations? The potential is a positive one. Rather than Turkish scholars attempting to participate as outsiders in core theoretical discussions by trying to explore the same questions - and possibly being viewed therefore as either superfluous to the discussion or worse yet as trying to "trip up" core theorists with examples from the Turkish experience - Turkish IR scholars may be better off participating as newcomer theorists, with their own set of questions, stemming from different contextual conditions.

In the natural tendency to create hierarchies, homegrown theorizing out of the periphery would probably in the short run take second seat to theorizing out of the core. On the other hand, such theorizing would recognize (à la Charles Taylor) the politics of difference of periphery theorists, and allow for the possibility of discovering what, for example, a Turkish version of IR theorizing might be like. The alternative seems to be a seemingly futile quest for Turkish (and other periphery) scholars, the ultimate goal of which is the dubious one of assimilation into one core theory community or another. ${ }^{3}$ Periphery scholars engaging in homegrown theorizing would trade the loss of some equality (which never really existed anyway) for a boost to distinctiveness, which may be the only route to another kind of equality. It seems a worthwhile exchange. An increase in homegrown theorizing out of the periphery will naturally spawn greater core-periphery dialogue on theory in IR - including projects such as this one on geocultural epistemologies - help to reduce the negative experiences of pigeon-holed periphery scholars, and ultimately improve IR theorizing overall by enriching its sources and perspectives.

\section{Notes}

1 A different version of this chapter has been published as "Periphery Theorizing for a Truly International Discipline: Spinning IR Theory Out of Anatolia," in the Review of International Studies, 34 (4), 2008.

2 "Workshop on IR Teaching in Turkey", held in 1996 at Middle East Technical University, Ankara; "Deconstructing and Redefining IR", held in May 2001 at Marmara University in Istanbul; "Workshop on the Study and Education of IR in Turkey", the minutes of which were published in a special volume of the journal Uluslararasi Iliskiler, 2 (6), summer 2005.

3 One wonders whether theorizing in the periphery might not turn out to be the next battlefield for transatlantic paradigm battles, as countering schools of thought from North America and Europe seek to gain prominence in newly emerging arenas. It could be argued, for example, that a work like Callahan's 2001 discussion of how IR theory is being built up in the Chinese context is critical of peripheral embracing of "rationalist" views on theorizing not due to concerns over incompatibility or inappropriateness of the perspective for that context, but rather due to concerns that American views on social science seem to be gaining prominence there.

\section{References}

Ari, Tayyar (2002) Uluslararasi iliskiler teorileri, Istanbul: Alfa Yayinlari.

Bilge, Suat (1962) Politika ogretimi sympozyumu, Ankara: Sevinc Matbaasi.

Callahan, William A. (2001). "China and the Globalisation of IR Theory: Discussion of 'Building International Relations Theory with Chinese Characteristics', Journal of Contemporary China, 10 (26): 75-88.

Dedeoglu, Beril (2005) "Workshop on the Study and Education of IR in Turkey," Uluslararasi Iliskiler, $2(6)$.

Gonlubol, Mehmet (1993) Uluslararasi politika: ilkerler, kavramlar, kurumlar (4th edn), Ankara: Attila Kitabevi. 
Karaosmanoglu, Ali (2005) "Workshop on the Study and Education of IR in Turkey," Uluslararasi Iliskiler, 2 (6).

Kut, Gun (2005) "Workshop on the Study and Education of IR in Turkey," Uluslararasi Iliskiler, 2 (6).

Lepgold, Joseph (1998) "Is Anyone Listening? International Relations Theory and the Problem of Policy Relevance,” Political Science Quarterly, 113 (1): 43-63.

Mathews, Julie (2007) "Predicting Students' Academic Success . . Is Not Always Enough: Assessing the Turkish Foreign Scholarship Program," Higher Education, 53 (5): 645-673.

Onulduran, Ersin (2005) "Workshop on the Study and Education of IR in Turkey," Uluslararasi Iliskiler, 2 (6).

Sezer, Duygu (2005) "Workshop on the Study and Education of IR in Turkey," Uluslararasi Iliskiler, 2 (6).

Sonmezoglu, Faruk (2000) Uluslararasi politika ve dis politika analizi (3rd edn), Istanbul: Filiz Kitabevi.

Taylor, Charles (1992) Multiculturalism and the "Politics of Recognition": An Essay, Princeton, NJ: Princeton University Press.

Wallace, William (1994) "Between Two Worlds: Think Tanks and Foreign Policy," in C. Hill and P. Beschoff (eds) Two Worlds of International Relations, London: Routledge.

Walt, Stephen M. (1987) The Origins of Alliances, Ithaca, NY: Cornell University Press. 